\title{
Reply to Letter re: Non-target Embolization or Local Effect of Infarction?
}

\author{
Jyotsna Acharya $\cdot$ Karen Bancroft $\cdot$ \\ James Lay
}

Received: 16 April 2013/Accepted: 18 April 2013/Published online: 15 May 2013

(C) Springer Science+Business Media New York and the Cardiovascular and Interventional Radiological Society of Europe (CIRSE) 2013

\section{Dear Sir,}

We thank the authors for their interest in our case report. The cause of perforation of transverse colon 3 months after uterine artery embolization cannot be established for certain, but the fact that the perforated colon is stuck down to the large necrotic fundal fibroid suggest that direct, local inflammatory involvement is likely. Small- or large-bowel injury from uterine artery embolization is surprisingly rare even for large fibroid uterus but a few cases have been reported previously $[1,2]$. We maintain that the risk of such complication is higher if a large serosal fibroid on the fundus of uterus is present, as in this case. If there is colonic infarction at the time of uterine artery embolization, it is not clear why the patient would have bowel perforation 3 months later, when there is a relative absence of symptoms of ischaemic bowel injury in the interim.

Finally, we are not advocating early laparotomy for all cases but where there is sufficient clinical concern and risk factors for bowel injury are present, even if imaging is normal, the risks of laparotomy may be outweighed by the benefits. As in the present case, where irrespective of the mechanism of large bowel injury, there seems to be no other way of treating such a catastrophic complication.

Conflict of interest None.

\section{References}

1. Goldberg J, Boyle K, Choi M et al (2005) Small bowel obstruction due to adhesive disease observed. Am J Obstet Gynaecol 193:892-893

2. Virmani V, Fasih N, Rakhra K (2011) Intraluminal bowel obstruction by a detached fibroid-an extremely unusual complication of uterine artery embolization. Clin Radiol 66:795-797

\footnotetext{
J. Acharya $(\square)$

8 Watermint Way, West Timperley, Altrincham, Cheshire

WA14 5YP, UK

e-mail: jyoacharya@yahoo.com

J. Acharya

Stepping Hill Hospital, Stockport SK2 7JE, UK

K. Bancroft · J. Lay

Royal Bolton Hospital, Minerva Road, Farnworth, Bolton, Lancashire BL4 0JR, UK

e-mail: karen.bancroft@boltonft.nhs.uk

J. Lay

e-mail: james.lay@boltonft.nhs.uk
} 